Marquette University

e-Publications@Marquette

Economics Faculty Research and Publications

Economics, Department of

$1-1-2002$

\title{
Collective Intentionality and Individual Behavior
}

John B. Davis

Marquette University, john.davis@marquette.edu

Published version."Collective Intentionality and Individual Behavior", in Intersubjectivity in

Economics : Agents and Structures. Eds. Edward Fullbrook. New York : Routledge, 2002: 11-27.

Publisher. (C) 2002 Intersubjectivity in Economics : Agents and Structures. Used with permission. 


\title{
COLLECTIVE INTENTIONALITY AND INDIVIDUAL BEHAVIOR
}

\author{
John B. Davis
}

In this paper I develop a heterodox economics account of how individuals influence institutions and social values. In contemporary economics there are two opposed ways of characterizing this influence. Mainstream economics treats institutions and social values as the products of atomistic individual activity, meaning that when individuals act, they act free of any significant social attachments. In contrast, heterodox economics treats institutions and social values as the product of socially embedded individual activity, meaning that when individuals act, they act socially or as members of various kinds of groups. The atomistic view has dominated economics for a half century or more. Thus, to make sense of this difference from a heterodox perspective, we need to show how individuals in groups act differently from groups of atomistic individuals, or how individuals acting in an organized way behave differently from unorganized collections of individuals. I understand the difference to be essentially a matter of explaining how individuals acting in groups have "shared" intentions about the groups of which they are members.

This distinction between "shared" intentions and ordinary individual intentions may seem relatively straightforward in everyday language, since people use "we" language in an intentional manner when they focus on their membership in groups ("what we want," "what our department decided," "what the community has chosen to do," etc.), and use "I" language when they see themselves as acting independently of others ("what I want," "what I believe," etc.). Yet, until recently the philosophical explanation of intentionality has been almost entirely associated with the explanation of individual intentions associated with the use of " $I$ " language. Moreover, proponents of individualist explanations in the social sciences and especially in economics argue that it makes no sense to ascribe intentions to groups of individuals, because only individuals can have intentions. For them, our ordinary ways of speaking are at best an ill-founded expedient, and a proper analysis of "we" language should reduce such expressions to sets of " $I$ " expressions. 


\section{J. B. DAVIS}

Here, my strategy is to develop an account of "shared" intention that answers these objections by drawing on a more recent philosophical literature on the subject of collective intentionality. In this literature, when we speak of individuals as being socially embedded, we mean that they have we-intentions, that is, intentions that they attribute - and believe that others attribute - to the group of which they are members. Though these we-intentions are often said to be "shared" in this literature, caution needs to be shown in using this term. Collective intentionality analysis is non-holistic, meaning that only individuals have intentions, not groups. Individuals attribute intentions to the groups of which they are members, and participate in this attribution by using "we" language. In this sense we-intentions are shared. But this does not imply that a group has an intention over and above the intentions of the individuals that make it up. We-intentions are individually expressed intentions, though of a special kind in making the group rather than the individual their subject. In what follows, then, only individuals exist in regard to intentional expression. The issue then becomes whether the relationships between individuals expressing we-intentions are compatible with characterizing individuals atomistically, or whether individuals" use of "we" language requires that we characterize individuals as being socially embedded.

This issue, however, cannot be kept separate from another. As I will argue, the most important consequence of treating individuals as being socially embedded in groups is that their behavior can no longer be explained solely in instrumentally rational terms. That is, when individuals are seen to be socially embedded in groups, the requirements upon them as members of those groups dictate that their behavior be explained as what I label a deontologically rational behavior or as "principled" rational behavior. Thus, if a collective intentionality analysis of individuals' use of "we" language implies that individuals cannot be conceived of atomistically, but must be thought to be socially embedded in groups, then it also implies that their behavior needs to be reconceptualized as well, with instrumental rationality taking a back seat to a deontologically rational or "principled" rational type of behavior.

In this chapter, I thus address the question of how individuals influence institutions and social values in terms of a conception of the individual as socially embedded, explaining this conception in terms of we-intentions, and drawing out the implications all this has for how we understand individual behavior. Section 1 introduces the concept of collective intentionality, relying on the thinking of the leading contributor to the subject, Finnish philosopher, Raimo Tuomela. Section 2 applies the collective intentionality concept to the agency-structure model as drawn from Tony Lawson (1997) to explain how individuals socially embedded in groups can be thought to influence institutions and social values through their ability to form we-intentions. Section 3 addresses how our understanding of individual 
economic behavior needs to be revised to include deontologically or "principled" rational behavior when we consider the socially embedded individual. Section 4 briefly comments on individuals' capacity to form we-intentions in terms of the idea of seeing things from others' points of view, and then summarizes the argument of the paper.

\section{Collective intentionality and individuals' influence on institutions and social values}

Until recently, analytic philosophers have explained the concept of intentionality - the idea that mental states have an "aboutness" to them in terms of the actions and intentions of individuals (e.g. Anscombe 1963; Davidson 1980). ${ }^{1}$ Having an intention involves settling on a course of action, either by deciding to act in some way or even by simply excluding considerations that favor alternative courses of action. Having an intention involves forming a commitment to action, and intentional action only occurs when an agent aims to bring something about by acting in a purposive way. But if a collection of individuals performs some set of actions as a group or team, and each individual acts intentionally, does this mean that the group acts intentionally as well, settling on a group course of action and making a commitment to action as a group?

In the atomist tradition, individuals form intentions and act, groups do not. Individuals may act as members of groups, but they still form their intentions individually, because only individual minds exist. Thus Hayek held that supra-individual entities such as groups, classes, etc. should be thought of as theoretical concepts rather than real things (e.g. Hayek 1955), and Arrow's assertion that "society" "is just a convenient label for the totality of individuals" (Arrow 1984: 80). From their perspective, because all intentionality is individual, collective intentionality must be a theoretical concept rather than a really existing thing. The alternative is to imagine some fanciful sort of Hegelian super-mind floating above and about individual minds. Yet, the dilemma this poses is a false one. We can say that all mental life occurs within individual minds, but this does not imply that all intentions are individual and must be expressed in first person singular terms. It is not incoherent for an individual to refer to a group of which that individual is a member, and say, "we intend," or to use first person plural expressions in a variety of circumstances to indicate what a group"s intentions might be. Nor does the use of "we-intentions" presuppose the existence of any sort of super-mind or other type of supraindividual entity. Indeed, since "we-intentions" language is as common in everyday life as "I intentions" language, there is every reason to investigate the implications of collective intentionality for economic behavior.

In the current philosophical literature on the subject, collective intentionality and we-intentions are explained as a structure of reciprocal 
attitudes shared by individuals. The main contributions may be found in Bratman (1993; 1999), Gilbert (1989), Searle (1990; 1995), Tuomela and Miller (1988) and Tuomela (1991; 1995). In the discussion that follows I rely on Tuomela's work, which is the most extensive and well-developed. Tuomela's analysis is conservative, in that though it sometimes makes reference to intentions as being shared, this is not meant to imply that there is any actual sharing of intentions, beliefs, desires, or other we-intentions by individuals using "we" language. Rather, a we-intention is an individual's attribution of an intention to a group that the individual believes is reciprocally held by other individuals in that same group. Indeed, an individual may have a we-intention that no other individuals actually have if that individual is mistaken about others having that we-intention. Thus, a we-intention is not a supra-individual group intention separate from the attributions of individuals. Rather, a we-intention is an individual's expression of a group intention based on a sense of there being like attributions on the part of others in the group to which the individual belongs. Thus, the expression "the intentions of the group" is really shorthand for a set of individual we-intentions on the part of a collection of individuals in the group.

Two characteristics of we-intentions are accordingly emphasized in Tuomela's analysis. First, the individual expressing a we-intention believes that this intention is widely if not universally held by other group members, and secondly, the individual believes this intention is mutually held by members of the group. (In the limiting case above both of these beliefs are mistaken.) Consider the case in which an individual's we-intention is rooted in an attitude ("fear") that the individual believes group members also attribute to the group. For an individual $\mathrm{A}$ who is a member of a group $G$, "A we-fears that $X$ if $A$ fears that $X$ and believes that it is feared in $G$ that $X$ and that it is mutually believed in $G$ that $X$ is feared in G" (Tuomela 1995: 38). On this basis A might suppose that G has some intention reflecting the fear of $X$. This we-intention would have the same structure as the attitude $A$ ascribes to the group. Of course, $A$ can only surmise that others in $G$ have the same fear and that the fear of $X$ is mutually believed by members of the group. Ideally, the idea that $X$ is "mutually believed" would involve saying that the fear that $X$ is believed by everyone, but Tuomela allows that "mutual" can have strong and weak interpretations, because groups themselves have strong and weak criteria for supposing their members share a belief, attitude, or intention. The main point is that we-attitudes a re group attitude, not in the sense that a group apart from its members has an attitude towards something, but in the sense that individuals "generally" in a group have some such attitude expressible in "we" terms. Thus, saying that they "generally" have a we-attitude depends not just on the mutual belief condition, but on both conditions, which if combined, provide us with 
reason to suppose that individual members of a group are justified in saying what they ("we") intend."

Note that this very basic understanding of collective intentionality already takes us some way towards understanding how individuals can be thought to influence institutions and social values. From an atomist point of view, the main difficulty in understanding how individual behavior influences institutions and social values lies in showing how something fundamentally individual in nature gets translated into something that is fundamentally social in nature. Thus, game theory accounts that attempt to explain how social conventions and institutions emerge from the choices of atomistic individuals are either forced to rely on ad hoc assumptions not explainable in terms of individual choice to get the job done, or they simply fail to get the job done (cf. Hargreaves Heap and Varoufakis 1995; Rizvi 1994). In contrast, when we suppose that individuals are socially embedded in groups and form we-intentions about those groups' activities, we have already assumed that individuals are engaged in social activity. Institutions and social values are products of social activity. What Tuomela's analysis adds to this basic idea is an explanation of social activity in terms of structures of reciprocally related we-intentions possessing a mutually reinforcing character. These structures of interaction, as it were, function as the skeletons of social activity and therefore of the institutions and social values that are the products of social activity. Thus, change and evolution in structures of we-intentions in groups bring about change and evolution in institutions and social values, and individuals influence institutions and social values as they continually form new and different we-intentions about the groups of which they are members.

Tuomela's analysis also provides a basis for distinguishing how individuals influence institutions as compared to how they influence social values. Using his distinction between rules and norms, we-attitudes and we-intentions associated with rules underlie institutions, and we-attitudes associated with norms underlie social values. With rules, an explicit or implicit agreement brought into existence by some authority determines a distribution of tasks and activities to individuals. Rules may be formal and written, such as laws, statutes, regulations, charters, by-laws, etc., or they may be informal agreements between individuals, sometimes orally established and sometimes silently agreed to. With norms, mutual beliefs substitute for actual agreements between individuals in determining distributions of tasks and activities across individuals. As with we-intentions generally, mutual beliefs are beliefs reciprocally established between individuals, such that each believes that others have the same belief, and each also believes that others think the same about the others, and so on in a structure of reinforcing, mutually held beliefs.

Rules and norms are both understood to have motivational force, meaning that they constitute reasons for action on the part of the individuals 


\section{J. B. DAVIS}

who accept them. Indeed, rules and norms are typically framed as "ought" principles, and impose requirements on individuals as members of groups in the form of specific prescriptions for individual action. Formally, individual $A$ feels obliged to do $X$, because $A$ is a member of the group with a we-intention representable in terms of a rule or norm to the effect, "we believe members of the group should do X." But rules and norms are different in virtue of the different means by which they enforce a distribution of tasks and activities among individuals (Tuomela 1995: 22-24). The prescriptive force of rules derives from there being sanctions that apply, whether formal / legal or informal, to those individuals who do not observe them. In contrast to rules, sanctioning with norms takes the form of approval or disapproval on the part of others. Because norms are internalized by individuals in that they themselves accept them as reasons for acting, individuals apply others' potential disapproval to themselves, as when feeling shame or embarrassment.

In Tuomela's collective intentionality analysis, then, rules are the basis for institutions, and norms are the basis for social values. While it is true that many institutions also involve norms, as relatively settled social arrangements institutions generally place greater reliance on rules. Social values, in contrast, are rarely rooted in agreements, even informally, and thus place little weight on rules. Rather, social values reflect systems of mutual belief about individuals' interaction with one another. Thus, when individuals create and/or change institutions, they adopt new rules, and produce new we-attitudes that define group action within an institutional framework characterizable in terms of agreements and corresponding sanctions. When individuals develop and / or influence social values, they adopt new norms, and produce new we-attitudes that define group action within a social value framework based on their mutual beliefs and systems of (dis)approval. In both frameworks, rules/institutions and norms/ social values, we-intentions are the foundation for understanding group action. Individuals thus influence institutions and social values as members of groups, and group action is the intermediate link between individual action and supra-individual institutions and social values missing from mainstream accounts of individuals' influence on institutions and social values.

To complete this picture, we need to briefly consider how rules and norms create obligations for individuals in terms of how different tasks, rights, and positions apply to different individuals in groups. Tuomela characterizes an individual's position within a particular group in terms of that individual's tasks and rights within that group. An individual's tasks and rights are then further distinguished according to whether they flow from rules or norms operating within the group, that is, whether they are rule-based tasks and rights or norm-based tasks and rights. Across groups, individuals' social positions are understood in terms of the whole 
array of actions individuals are required and permitted to do across various economic settings. These social positions assign individuals a variety of different tasks whose performance is, in each instance, protected by rights, where these tasks-rights combinations may themselves exist within established modes of implementation that are also understood in tasks-rights terms. The overall framework thus explains individual rights and duties within and across groups in terms of tasks-rights pairs that ultimately have we-attitudes in groups as their foundation. Individuals influence institutions and social values by acting within this framework.

\section{The agency-structure model with collective intentionality}

I focus on the agency-structure model, first, because it describes human agency as an "embedded intentional causality" and human rationality as a situated rationality (Lawson 1997: 63, 187), and, second, because it describes not only how individuals are influenced by institutions and social values, but also how they influence institutions and social values. A precursory formulation of the model is Anthony Giddens' influential "structuration theory," which treats individuals and social structures as interdependent, or as a duality, such that each may be said to help constitute the other, especially through recurrent social practices $(1976 ; 1984)$. Roy Bhaskar (1979 [1989]) and Margaret Archer (1995) revised and extended Giddens' thinking, principally by seeing reality as stratified and multi-layered with emergent properties differentiating one layer or level from another (cf. Hodgson 2000: 5-13; also Collier 1994). Lawson developed this latter, critical realist conception of the agency-structure relationship specifically for economics in Part III of his Economics and Reality (1997), and used it primarily to critique the methodological posture of mainstream economics. An important aspect of Lawson's analysis is that individuals engage in routinized forms of activity, rely on tacit knowledge and skills, and observe rules, norms and conventions. What, then, does the concept of collective or group intentionality add to this account?

In the first place, the concept of collective intentionality permits us to develop a more concrete understanding of individuals' embeddedness and situated rationality in terms of the ways in which groups of individuals are organized. Groups, in virtue of their complexity, are organized so as to assign power and responsibility differently to individuals in different positions, yet, in virtue of their having "shared" intentions, still in a manner that aims at consistency in overall action across these assignments. Focusing on individuals' involvement in groups allows us to explain why individuals engage in particular types of routinized activity, what particular tacit knowledge and skills they need to rely upon, and what particular rules, norms, and conventions they need to observe based on the way that the group as a whole organizes a set of positions in a 


\section{J. B. DAVIS}

relatively coherent structure. Simply referring to individuals' reliance on routines, tacit abilities, and so forth fails to account for why different individuals act in different ways, and therefore, ultimately, how changes in the ways that individuals act in concert with one another influences institutions and social values. Individuals act in the ways that they do, because they occupy particular positions in groups organized in terms of collections of positions (cf. Lawson 1997: $163 \mathrm{ff}$ ).

But more is involved than simply adding new detail to our analysis of individual embeddedness and to the account of the influence of individuals on institutions and social values. When individuals act under rationales involving we-intentions, groups become agents over and above the collection of individuals that make them up. Individuals' actions still have effects, but specifically as a particular pattern of effects that can be identified as the effects that the group has as a distinguishable agent in its own right. Tuomela's account of collective intentionality, in explaining collective intentionality and "shared" intention as a structure of individual intentions, at once combines the causal effectivity of individual action with the fact of individuals' organization in groups to justify treating groups as cohesive, single agents. Thus the fact that individuals follow routines, adopt norms, etc. is not just evidence that human agency involves an "embedded intentional causality" and a situated rationality, but it is evidence that individuals influence institutions and social values by way of the group structures in which individuals are embedded.

But one point needs clarification. We saw above that mainstream economics lacks an account of how groups mediate between individuals and institutions and social values, and that this tends to produce a reliance on ad hoc assumptions in efforts to explain how individuals influence institutions and social values. Given that such explanations enjoy limited success at best, it does not come as a surprise that the language of "unintended consequences" strongly underlies 'mainstream economics' accounts of the relation of individuals to institutions and social values. But this reliance should not be thought to imply that, when we turn to collective intentionality analysis of groups, that institutions and social values are fully intended consequences of the activities of individuals in groups. In the first place, in the agency-structure model, structure, or institutions and social values also influence individuals (just as they are influenced by individuals), and this causal process makes the evolution and development of institutions and social values an open-ended process with unintended consequences. But there are other reasons specific to the operation of groups which lead us to the same conclusion.

First, the number and variety of kinds of groups which exist in human society is truly staggering, ranging from more tightly organized groups such as firms, governments, and households (March and Simon 1956) to more loosely formed ones such as social movements or even just two 
individuals "going for a walk together" (Gilbert 1989). Indeed, if we add to groups in this more "objective" rule-governed sense all those collections of individuals who constitute groups in the more "subjective" sense of adhering to shared social values, then the number of groups is even larger. Second, membership in and across groups is obviously cross-cutting, overlapping, and often conflicting. Add to this the fact that membership in groups is continually changing, and we have further reason to expect considerable "unintended consequences" in our analysis. Third, groups however defined, do not make up the entire universe of economic agents. Individual action that is relatively autonomous (if not atomistic) also contributes to the evolution of institutions and social values. For these reasons, the activity of groups of individuals ought only be said to influence rather than fully explain or determine the evolution of institutions and social values.

What general methodological strategy does the collective intentionality account of individuals as socially embedded thus add to the agencystructure model? First, we begin by surveying and identifying particular groups of individuals acting as economic agents, where the selection of those groups that are of interest to us is driven by our current causeand-effect concerns presented to us in the form of "why" questions regarding the way things happen in the economic world (Runde 1998). Second, our characterization of these groups involves our explaining their position-task-right structures, which accounts for their internal organization and their capacity to coherently organize the different activities of different individuals. Third, we attempt to explain interaction between groups, where this involves institutions or social values with acrossgroup rules and norms. This broader framework is no less a domain of collective intentionality, though it stretches the idea of a group to think of institutions and social values being groups.

\section{A revised view of individual economic behavior}

I now turn to why our understanding of individual economic behavior needs to be revised when we make use of the concept of collective intentionality. The behavior of atomistic individuals is understood in instrumentally rational terms, because individual objective functions are defined solely in terms of individuals' own preferences. With no basis for action other than their own preferences, and assuming that they do not act out of habit or behave irrationally, atomistic individuals can do nothing other than attempt to realize their own preferences as efficiently as possible. When we treat individuals as socially embedded, however, we can no longer say that individuals act only on their own preferences, because socially embedded individuals generally act in accordance with those rules and norms associated with their membership in groups. These rules 
and norms, we saw, function as "ought" principles or social requirements, and as such generally lead socially embedded individuals to behave in ways different from the ways that atomistic individuals behave. It is this emphasis on "ought" principles and the social requirements of group membership, then, that is at odds with explaining the behavior of socially embedded individuals in instrumentally rational terms, and suggests that socially embedded individuals are fundamentally different from atomistic individuals.

Those who defend the atomistic conception of the individual and instrumental rationality would likely first reject these arguments for the following reason. Explaining individual behavior in terms of group requirements is ultimately equivalent to explaining individual behavior as instrumentally rational though now subject to constraints additional to those usually assumed in standard constrained optimization analysis, namely, constraints associated with observing the rules and norms of group membership. These additional "social" constraints further narrow individuals' choice sets, but individuals still ought to be thought to maximize their preferences within this additionally delimited space. Even socially embedded individuals, that is, ultimately behave in an instrumentally rational fashion, and it thus follows that socially embedded individuals are not different in any substantive sense from atomistic individuals.

This response, however, overlooks what is different about individual behavior in groups in which individuals express we-intentions. On the understanding developed by Tuomela and others, since we-intentions are the intentions of individuals and not the intentions of groups, whatever these intentions imply in the way of individual behavior - say, that one ought to observe group rules and norms - must be thought of as having been intended by the individuals who have them. That is, intentional behavior, whatever its nature, reflects what the individual chooses to do, not what the individual is limited to doing. In the language of mainstream rationality theory, we-intentions derive from individuals' objective functions no less than do those individual intentions standard theory would associate with individuals acting on own preferences. Thus, acting in accordance with rules and norms is not evidence of acting under an additional set of constraints ("social" constraints). And since rules and norms impose requirements on individuals, supposing we-intentions derive from socially embedded individuals' objective functions, it gives us good reason to think individual behavior cannot be explained in instrumentally rational terms.

But might not defenders of the atomistic conception of the individual and instrumental rationality use this reply for one further defense of the standard conception? If we-intentions enter individuals' objective function, they might argue, then they must be produced by we-preferences, just as ordinary individual intentions are produced by own preferences 
(or I-preferences). If this is so, thus might not the behavior of socially embedded individuals still be explained in instrumentally rational terms? Indeed we-preferences have recently been analyzed along these lines by Robert Sugden in the form of team preferences (Sugden 2000). Sugden explicitly rejects collective intentionality analysis as carried out by Tuomela and others, precisely because it introduces the idea that individuals are bound by social obligations (or group requirements) which he regards as being inconsistent with an account of instrumentally rational behavior. To preserve the latter, then, the former has to go. This, in turn, would imply that rules and norms are things teams prefer to observe rather than believe their members are compelled to observe. Moreover, if this is all true, then it is hard to see why, with a team preferences analysis of rules and norms, individuals should be treated as socially embedded. If their we-intentions derive from we-preferences, and consequently impose no obligations or requirements upon them, it seems that their relationship to others is incidental to their behavior. Indeed, Sudgen effectively takes this position when he argues that the "existence" question regarding whether teams and other groups exist is independent of the theory of (instrumental) rationality enlarged to include we-preferences. In the final analysis, Sugden's view is that the conception of the individual as an atomistic being is sufficient for any discussion of we-preferences, we-intentions, and action in accord with rules and norms.

Clearly, Sugden's analysis turns on the idea that we-preferences do not impose "ought" principles or social requirements upon individuals. Why is it, then, that Tuomela and other proponents of collective intentionality see this as an essential dimension of we-intentions? The answer lies in their specific understanding of we-intentions. Individual we-intentions are what individuals think are the intentions of individuals in a group generally. They are not what individuals think ought to be the intentions of the group, nor are they the intentions of the group from any individual's own particular point of view. Since successfully expressing weintentions requires that an individual believe that other individuals have that same we-intention and also believe that this we-intention is mutually believed, an individual's expression of a we-intention basically involves the individual's best guess regarding a structure of intentions on the part of different individuals regarding what they all think everyone else believes is the intention of the group. But this means that there is a tension of some kind within the individual between this best guess view and whatever might be this individual's own view of what the group intends. This tension is a product of the fact that one does not use "we" language properly unless one makes a best effort to get at what everyone else means in using "we." In effect, an individual using "we" language must make a commitment to a group's view of its intentions irrespective of whether the individual personally agrees about this use of "we." For this 
reason, using "we" language and expressing we-intentions in the collective intentionality sense imposes obligations on individuals associated with standing by whatever the group's intention involves. Moreover, an obligation in this sense is not just something that binds an individual, but also a binding that the individual embraces. One only feels a genuine obligation, that is, when one has embraced that obligation oneself.

Sugden's treatment of we-preferences as preferences of instrumentally rational atomistic individuals consequently does not really get at what is involved in we-intentions. We-intentions do not derive from we-preferences, but rather from individual commitment to a use of "we" language that (self-) imposes obligations on the individual. But atomistic individuals do not act out of any such sense of obligation but only on the basis of what they prefer. Moreover, in Sugden's we-preference analysis, the individual's relation to others is an incidental one. We-preferences are held in essentially the same way by all team members, and there is no difference between the way we-preferences properly represent the team and the way an individual might understand the team's we-preferences. In contrast, we-intentions require the individual's commitment to the use of a shared we-language that goes beyond individual perspective. This, and the obligation it brings, socially embeds the individual in the group, and brings about a non-incidental relationship between the individual and others.

As said above, acting out of a sense of obligation or the requirements upon oneself may be characterized as being deontologically rational rather than instrumentally rational. Philosophers have traditionally seen the difference as being a matter of doing what one thinks one ought to do as opposed to doing what one wants to do. This may well suggest that what is meant here is that being deontologically rational is equivalent to acting morally, and that, therefore, the behavior of socially embedded individuals needs to be explained in terms of the categories of ethics. It is true that philosophers of ethics have used the term "deontology" to refer to a particular (non-consequentialist) approach to moral behavior. But clearly, many, if not most, of the obligations and requirements that groups impose upon individuals have little to do with acting morally. The term "ought," of course, is also used in a non-normative, pragmatic sense. It is this sense of the term that I generally mean to refer to when I characterize socially embedded individuals as acting in a deontologically rational way. Indeed, the second expression used above to characterize acting out of a sense of obligation or in terms of group requirements acting in a "principled" rational way - is probably the better one to employ. Individual action in groups is guided by a variety of principles, whose observance can be thought rational in a broad sense. For example, accepting the tasks assigned to one in an agreed-upon division of labor would be thought by most people to involve acting on a rational principle. Nor would it be said that a principle of this nature has any special 
moral content. Such principles simply constitute working principles in the operation of many groups. I thus characterize their observation by individuals as a "principled" type of rational behavior, and leave it to another occasion to investigate the extent to which such behavior also raises questions of morality.

My general argument, it should also be emphasized, is not that socially embedded individuals behave only in a "principled" rational fashion. Individuals who express we-intentions and are members of groups clearly also have their own preferences, and may seek to realize them in an instrumentally rational manner, either when they find themselves at odds with what is expected of them in groups, or even when they see themselves as acting in conformity with what the group expects of them. Indeed, in the organization of many groups, individuals are expected to act in an instrumentally rational way in order to best fulfill the requirements of group membership. Consider an employee in a business assigned a set of rule and norm-based tasks associated with doing a particular job. If one rule is to invoice customers by the end of the month, and the norm for how this is to be done is to include in the invoice a complete description of all purchases made by those customers, the individual assigned these tasks is likely still free to perform them in a variety of ways (inquire as to customer satisfaction, pursue follow-up orders, institute new record-keeping practices, etc.). How well individuals do their assigned jobs, then, can be a matter of the extent to which they also act on their own preferences regarding the way a job is best done. They consequently act in an instrumentally rational way when already behaving in a "principled" rational manner.

Individuals, it thus seems fair to say, engage in both instrumentally rational and "principled" rational kinds of behavior, and that the balance or mix of these depends upon the circumstances and the setting. Abstractly, one might begin by imagining a spectrum. At one extreme, there exists a set of activities in which individuals operate free of significant group attachments, and can be described as behaving solely in an instrumentally rational manner. This is the case that mainstream economists have treated as universal. At the opposite extreme, there exists a set of activities in which individuals act solely according to the dictates of the group, and their behavior is fully explained by group membership. Heterodox economists have on occasion seen this as the universal case (for example, in some Marxist accounts when class is said to determine individual behavior). But between these two extremes lies a variety of activities and what is probably the great majority of types of economic behavior. This behavior is complex in involving both instrumentally rational and "principled" rational behavior in some overall structure, and developing explanations of this large range of cases seems to be a matter of explaining how these two forms are integrated and organized with 


\section{J. B. DAVIS}

respect to one another. ${ }^{3} \mathrm{My}$ view is that explaining these types of cases should be the first goal of economists trying to describe individual behavior.

\section{The capacity to express we-intentions; summary}

I close with a brief discussion of why we should suppose that individuals are socially embedded in the sense of having a capacity to form weintentions. The capacity to express we-intentions is a capacity to remove oneself from one's own particular case and circumstances, and adopt a point of view held by others. When an individual uses "we" language correctly, that individual successfully grasps how a structure of we-attitudes on the part of individuals in a group justifies that individual saying what the group's intentions are. The closest mainstream economists come to this sort of explanation is in their treatment of sympathy as a possible argument in the atomistic individual's own objective function. Individuals who are sympathetic towards others are sometimes said to be "altruistic" in having preferences regarding others' well-being. But this conception involves an understanding of altruism at odds with what most people associate with the concept, since the "good" acts that these "altruistic" individuals engage in are only undertaken because they raise these individuals' own utility. Most people, rather, see altruistic behavior as a kind of selfless behavior. Sympathy explained in this way does not really involve individuals removing themselves from their own circumstances, or becoming selfless. It consequently does not get at what is involved in being able to express we-intentions which take individuals beyond their own cases.

One way of explaining this capacity to remove oneself from one's own particular case and circumstances lies in terms of Philippe Fontaine's recent treatment of the concept of empathy in early and later history of economics (Fontaine 1997; 2001). Fontaine distinguishes between sympathy and empathy, where sympathy is having an own preference regarding another's well-being, and empathy involves imagining oneself being in the place of another. If one is empathetic towards another person, one somehow grasps what the other's situation involves (an imagined transposition of places), and then acts in one's own capacity with that understanding in mind. Empathetic individuals, however, need not have other individuals' well-being in mind when they act. They may simply register how others look at the world, in order to make better decisions on their own. ${ }^{4}$ But empathy, in the sense of imagining another's circumstances, would also allow for altruistic behavior in the strong sense, in that one could behave sympathetically toward another having grasped what the other's situation involved. Thus, Fontaine distinguishes between imagining oneself in the place of others by intellectually appreciating their circumstances as compared to imagining oneself in the place 
of others by embracing their feelings and attitudes. That latter transposition could give rise to altruistic behavior when one was sympathetic toward those feelings and attitudes, though of course it could also give rise to quite the opposite type of behavior were those feelings and attitudes not thought admirable.

Fontaine's account of how individuals may remove themselves from their own circumstances is quite like the capacity Tuomela and others interested in collective intentionality attribute to individuals who have we-intentions. There is a difference, however. Fontaine's transposition of places involves an individual imagining the situation of another individual. But the capacity to form we-intentions is more abstract than this. When individuals successfully express we-intentions, they grasp how a reciprocal use of "we" language, backed up by a mutual belief condition across many individuals, entitles them to say what a group's intentions are. Thus, the business of removing oneself from one's own circumstances is less a matter of seeing things from someone else's point of view, and rather more a matter of grasping how a structure of we-intentions emerges across many individuals. Nonetheless, there is a clear point of contact between the two conceptions. While collective intentionality analysis attributes a capacity to individuals to grasp a structure of weintentions within a group, being able to do this could be argued to presuppose that individuals are able to place themselves in the shoes of one individual after another in a group to produce that sense of what the structure of we-intentions in the group is. That is, individuals arguably engage in a sampling of other's views, removing themselves from their own individual circumstances in doing so, as they develop an understanding of the correct use of "we" language in the group. Fontaine's individual-to-individual transposition of places analysis, then, might be thought to underlie collective intentionality's assumption of a capacity on the part of individuals to form we-intentions.

To summarize, what the discussion in this paper attempts to do is provide an account of individuals as socially embedded so as to be able to explain how individuals influence the development and evolution of institutions and social values. Individuals are characterized as being socially embedded when they are members of groups in which "we" language is used. Collective intentionality analysis, as recently developed in philosophy, is employed to explain individuals' use of "we" language, and then this conception of the socially embedded economic agent is introduced into agency-structure thinking about how individuals and institutions/social values influence one another. A key implication of the discussion is that individual behavior cannot be understood solely in instrumentally rational terms, but needs to be enlarged and modified to accommodate individuals" deontologically rational or "principled" rational behavior in groups. Whether or not such behavior actually 


\section{J. B. DAVIS}

occurs, and thus whether individuals can indeed be characterized as socially embedded, ultimately depends on whether one believes individuals can form we-intentions in the sense explained here. That they do have this capacity is suggested by the idea that individuals can imagine and place themselves in one another's places.

\section{Notes}

1 The analytic conception follows an earlier continental philosophy understanding of intentionality that began with the work of Franz Brentano, and was further developed in the phenomenological work of Edmund Husserl. My focus on the literature from analytic philosophy is motivated by this tradition's emphasis on the conditions of individuality.

2 Tuomela draws on an account of mutual belief that has become fairly standard among philosophers which relies on the idea of a hierarchical set of beliefs iterated across individuals (Tuomela 1995: 41ff). See Lewis (1969: 52ff) for a parallel account in terms of common knowledge that has played a role in game theory.

3 For one example of how such an explanation might be produced, see Minkler (1999), where a "commitment function" is added to a standard utility function representation of individual behavior. The individual is said to engage in a twostep iterative procedure with the first step corresponding to a response to group requirements and the second step corresponding to an instrumentally rational maximization of utility.

4 I use this understanding of empathy in my discussion of Keynes's treatment of investment in the stock market as like a newspaper beauty contest (Davis 1994: 130ff).

\section{References}

Anscombe, G. E. M. (1963) Intention, Oxford: Basil Blackwell.

Archer, M. (1995) Realist Social Theory: The Morphogenetic Approach, Cambridge: Cambridge University Press.

Arrow, K. J. (1984) The Economics of Information, Cambridge, MA: Belknap Press of Harvard University.

Bhaskar, R. (1979 [1989]) The Possibility of Naturalism: A Philosophic Critique of the Contemporary Human Sciences, 2nd edn. Brighton: Harvester.

Bratman, M. (1993) "Shared intention," Ethics 104, 97-113.

Bratman, M. (1999) Faces of Intention, Cambridge: Cambridge University Press.

Collier, A. (1994) Critical Realism: An Introduction to Roy Bhaskar's Philosophy, London: Verso.

Davidson, D. (1980) Essays on Actions and Events, Oxford: Clarendon Press.

Davis, J. (1994) Keynes's Philosophical Development, Cambridge: Cambridge University Press.

Fontaine, P. (1997) "Identification and economic behavior: Sympathy and empathy in historical perspective," Economics and Philosoplty 12(2), 261-80.

Fontaine, P. (2001) History of Political Economy, forthcoming.

Giddens, A. (1976) Central Problems in Social Theory, Berkeley: University of California Press. 
Giddens, A. (1984) The Constitution of Society, Cambridge: Policy Press.

Gilbert, M. (1989) On Social Facts, London: Routledge.

Hargreaves Heap, S. and Varoufakis, Y. (1995) Game Theory: A Critical Introduction, London: Routledge.

Hayek, F. (1979) The Counter-revolution in Science: Studies on the Abuse of Reason, Indianapolis, Indiana: Liberty Press.

Hodgson, G. (2000) "Structures and Institutions: Reflections on Institutionalism, Structuration Theory and Critical Realism," (unpublished).

Lawson, T. (1997) Economics and Reality, London: Routledge.

Lewis, D. (1969) Convention: A Philosophical Study, Cambridge, Mass.: Harvard University Press.

March, J. and Simon, H. (1956) Organizations, New York: Wiley.

Minkler, L. (1999) "The problem with utility: Toward a non-consequentialist/utility theory synthesis," Review of Social Economy 52(1): 4-24.

Rizvi, S. A. T. (1994) "Game Theory to the Rescue?" Contributions to Political Economy 13: 1-28.

Runde, J. (1998) "Assessing causal economic explanations," Oxford Economic Papers 50: 151-72.

Searle, J. (1990) "Collective intentions and actions," P. Cohen, J. Morgan and M. E. Pollack (eds) in Intentions in Communication, Cambridge, Mass.: MIT Press.

Searle, J. (1995) The Construction of Social Reality, New York: Free Press.

Sugden, R. (2000) "Team preferences," Economics and Philosophy 16(2): 175-204.

Tuomela, R. (1991) "We will do it: An analysis of group intentions," Philosophy and Phenomenological Research 51: 249-77.

Tuomela, R. (1995) The Importance of Us: A Philosophical Study of Basic Social Notions, Stanford: Stanford University Press.

Tuomela, R. and Miller, K. (1988) “We-intentions," Philosophical Studies 53: 367-89. 